\title{
Synthesis of Novel Virus-Like Mesoporous Silica-ZnO-Ag Nanoparticles and Quercetin Synergize with NIR Laser for Omicron Mutated Covid-19 Virus Infectious Diseases Treatment
}

\author{
Fadi Ibrahim \\ Department of Chemistry, Al Shujaa Bin Al Aslam School, Farwaniya, Kuwait \\ Email: fed_ooo@yahoo.com
}

How to cite this paper: Ibrahim, F. (2022) Synthesis of Novel Virus-Like Mesoporous Silica-ZnO-Ag Nanoparticles and Quercetin Synergize with NIR Laser for Omicron Mutated Covid-19 Virus Infectious Diseases Treatment. Advances in Nanoparticles, 11, 13-22

https://doi.org/10.4236/anp.2022.111002

Received: August 13, 2021

Accepted: February 7, 2022

Published: February 10, 2022

Copyright $\odot 2022$ by author(s) and Scientific Research Publishing Inc. This work is licensed under the Creative Commons Attribution International License (CC BY 4.0).

http://creativecommons.org/licenses/by/4.0/

(c) (i) Open Access

\begin{abstract}
This work shows that novel virus-like mesopore silica-zinc oxide/Ag nanoparticles (SZnOAg) synthesized and professionally collected on NIR laser irradiation with quercetin to improve the elimination the mutated virus as a biomedical application. A unique type of silica nanoparticles with a self-inflating tubular surface has been successfully synthesized using a novel single-micelle epitaxial growth process. The properties of the nanoparticles can be tuned with respect to their core diameter, tubular length, and outer diameter. Due to their biomimetic appearance, they can rapidly transform living cells into virus-like particles, this SZnOAg nanomaterial has specific elimination effect on bacteriophage and Covid-19. Using epitaxial growth, we can construct virus-like structures that can be used for biomedicine applications. These nanomaterials and NIR laser could open the way to a new range of antiviral materials, due to the low-efficiency cellular uptake of current nanoparticles, their applications in the biomedical field are limited. Herein, it clearly shows that novel mesoporous silica nanoparticles can be easily exhibited superior cellular uptake property.
\end{abstract}

\section{Keywords}

Bacteriophage, Biomedical Applications, Covid-19, Omicron, Epitaxial Growth Zinc/Silica/Silver Nanoparticles, Infectious Diseases, NIR Laser, SEM/TEM, Photothermal, Quercetin, Virus-Like Mesopore

\section{Introduction}

Nanoparticles have been designed for biomedical applications such as intracel- 
lular drug delivery and molecular imaging [1] [2] [3] [4] [5]. Their efficiency heavily relies on the cellular uptake performance [6] [7] [8] [9]. The interaction between nanoparticles and biological hosts (e.g., HeLa cell, Escherichia coli) plays an important role in the cellular uptake process, which is greatly dependent on the chemical and physical properties of the nanoparticles [10] [11] [12]. Previous reports have introduced various methods to enhance the cellular uptake property by controlling factors that could influence the interaction between nanomaterials and biological hosts, such as chemical composition, particle shape, and surface charge [13] [14] [15] [16]. However, studies on regulating the interaction between nanomaterials and biological hosts by improving the surface topological structures of nanomaterials are relatively rare [17]-[22]. In addition, Ag NPs showed average size of $\sim 15 \mathrm{~nm}$ [23].

\section{Ease of Use}

In this work, uniform ease synthesized virus-like mesoporous silica-zinc oxide with Ag nanoparticles (SZnOAg) have been successfully synthesized using a single micelle epitaxial culture reaction. [24] [25] The nanoparticles were fully developed and exhibited uniform surface characteristics via a novel single micelle epitaxial growth approach in a low-surfactant-concern oil/water bi-phase reaction system, with the using of hexadecyltrimethylammonium bromide (CTAB) as a structural template and tetraethyl orthocarbonate (TEOC) as a precursor. [26] The virus-like particles of mesoporous silica exhibit a uniform particle size and a well-controllable inner diameter. They can also form a rough surface structure by growing radially from the inner portions of the silica nanospheres. Also, the virus-like nanoparticles have unique internalization pathways.

\section{Aim of the Work}

Inhibit virus spreading by using omicron virus-like nanomaterials and NIR-Laser system. Uniform virus-like mesoporous silica-zinc oxide nanoparticles can be synthesized in a bi-phase reaction system with a low surfactant concentration, which allows the assembly of reactants to take place at the oil-water interface for continuous interfacial growth [27].

\section{Materials and Methods}

\subsection{Materials}

The oil phase was adopted in the upper of the beaker to be a (TEOC) solution in hydrophobic organic solvent (such as cyclohexane), while the bottom water phase was an aqueous solution of cationic surfactant (CTAB) as a template and $\mathrm{NaOH}$ as a catalyst. Scanning electron microscopy (SEM) and transmission electron microscopy (TEM) images of the obtained mesoporous silica nanoparticles clearly show a unique virus-like morphology with uniform particle size of $\sim 160 \mathrm{~nm}$ (Figure 1). Quercetin is one of the most important flavonoids and belongs to the class of flavanol's [28]. 

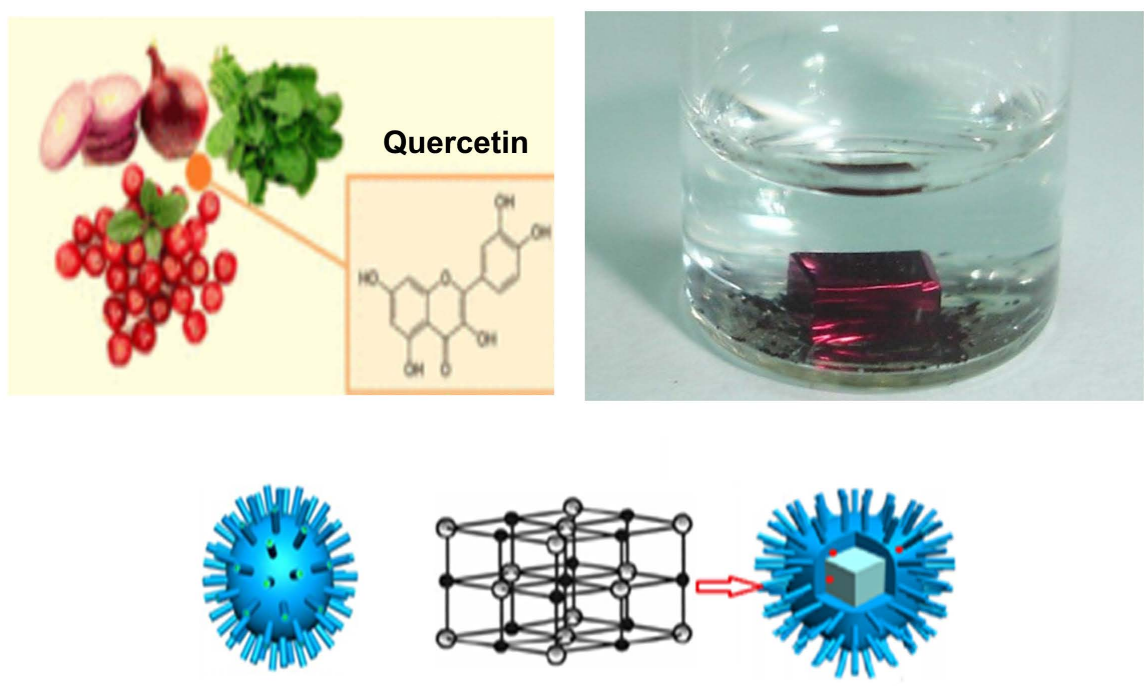

SZnOAg

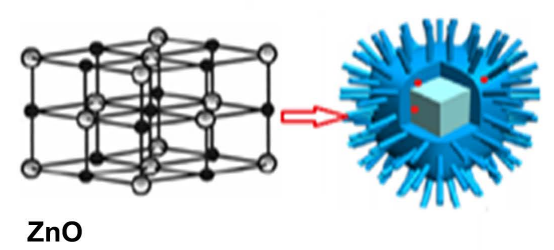

Figure 1. Quercetin and virus-like mesoporous silica-ZnO-Ag nanoparticles with inner portions of the silica nanospheres consist of $\mathrm{ZnO} / \mathrm{Ag}$ cubic cluster with hexadecyltrimethylammonium bromide (CTAB) as a structural template and tetraethyl orthocarbonate (TEOC) as a precursor.

\subsection{Methods}

In this framework, experimental results have demonstrated that quercetin exerts strong inhibitory effects on ACE2 in vitro, and in vivo when tested in rats [29]. Furthermore, the screening of a library of 150 compounds, allowed the identification of quercetin as a potent inhibitor of SARS-CoV-2 3CLpro [30]. Taken together, these results suggest that quercetin may prevent the entry of SARS-CoV-2 in the host cell, binding the S-protein and inhibiting ACE2 receptors [31].

\section{Statistical Analysis}

In this study, we consider the bacteriophage as a target virus, this virus has a symmetrical structure, approximately $57 \mathrm{~nm}$ wide and $100 \mathrm{~nm}$ long, with very long double-strand DNA in the head [32]. We then clearly demonstrate the specific elimination of bacteriophage bound to the complex, through the photothermal effect of the SZnOAg backbone under NIR laser irradiation $(1060 \mathrm{~nm})$. The irradiated solutions of SZnOAg-bacteriophage complexes $\left(300 \mu \mathrm{g} \cdot \mathrm{ml}^{-1}\right)$ in PBS ( $1 \mathrm{ml}$ ) by using a $1060 \mathrm{~nm}$ laser (5 W) (Figure 2); we also irradiated PBS alone $(1 \mathrm{ml})$ as a control. We measured the temperature of the solutions (away from the laser beam) at 1 min intervals by using a mercury thermometer. We measured the temperature of the solutions (away from the laser beam) at $1 \mathrm{~min}$ intervals by using a mercury thermometer. Under the NIR laser irradiation (1060 $\mathrm{nm}$ laser irradiation, $1 \mathrm{~W} \cdot \mathrm{cm}^{-2}, 15 \mathrm{~min}$ ), hyperthermia generated by mesoporous nanoparticles destroying virus cell membrane and biofilm promoting and increasing $\mathrm{Ag}^{+}$release from the nanocarrier, resulting in photothermal-enhanced antibacterial activity. 


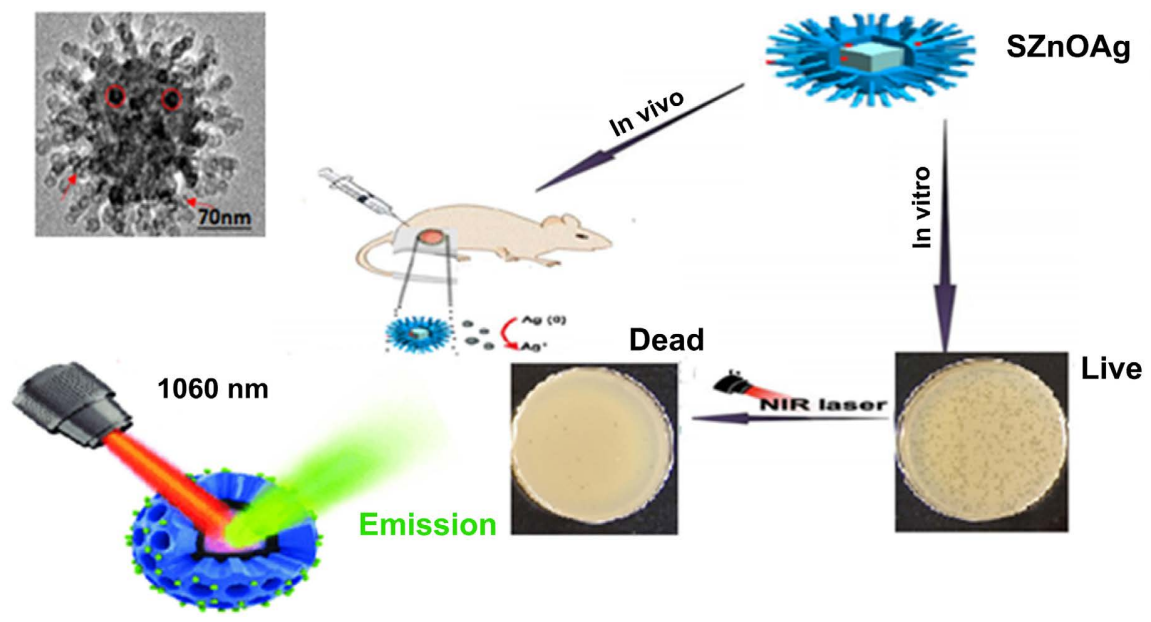

Figure 2. Schematic description photothermal effect of the quercetin and SZnOAg under NIR laser irradiation (1060 $\mathrm{nm}$ ) and its synergistic antiviral effects.

\section{Results}

Spherical nano-systems with average size and pores of $200-240 \mathrm{~nm}$ and $3.4-4.8$ $\mathrm{nm}$, respectively were successfully fabricated. In vitro antibacterial activity was evaluated against Virus cells by adding SZnOAg with laser irradiation at same concentration $\left(128 \mu \mathrm{g} \cdot \mathrm{mL}^{-1}\right), 22 \%$ and $76 \%$ of cells death were achieved [33]. Results corroborate antibacterial assays displaying a NIR-responsive $\mathrm{Ag}^{+}$release, with $11.3 \%$ and $37.3 \%$ of release with laser irradiation, respectively, which indicate that multimodal synergistic therapy on $\mathrm{SZnOAg}$ with laser irradiation based could effectively treat MRSA skin infection. Beyond that, the animals evaluated showed no obvious changes in their body weight suggesting no biotoxicity. These findings made $\mathrm{ZnO}$ and $\mathrm{Ag}$ nanomaterials a promising multimodal nanoplatform against bacterial infections and for further clinical translations. Single $\mathrm{ZnO}$ nanoparticle was formed by uneven surface, which showed crystallinity with $\mathrm{d}$-spacing of $0.265 \mathrm{~nm}$ for nanocrystal as shown in Figure 3. The aggregates generated a macro-mesoporous network based on interparticle interactions.

The virus-like nanoparticles' rough surface morphology results mainly from the mesoporous silica nanotubes spontaneously grown via an epitaxial growth process. The obtained nanoparticles show uniform particle size and excellent monodispersed. The structural parameters of the nanoparticles can be well tuned with controllable core diameter $(\sim 50-180 \mathrm{~nm})$, tubular length $(\sim 7-80$ $\mathrm{nm})$, and outer diameter $(\sim 6-11 \mathrm{~nm})$. Thanks to the biomimetic morphology, the virus-like nanoparticles show greatly superior cellular uptake property (invading living cells in large quantities within few minutes, $<5 \mathrm{~min}$ ), unique internalization pathways, and extended blood circulation duration $(\mathrm{t} 1 / 2=2.16 \mathrm{~h})$, which is much longer than that of conventional mesoporous silica nanoparticles $(0.45 \mathrm{~h})$. Furthermore, our epitaxial growth strategy can be applied to fabricate various virus-like mesoporous core-shell structures, paving the way toward designed synthesis of virus-like nanocomposites for biomedicine applications [34]. Figure 4 shows X-ray diffraction pattern of zinc oxide. For atomic composition 

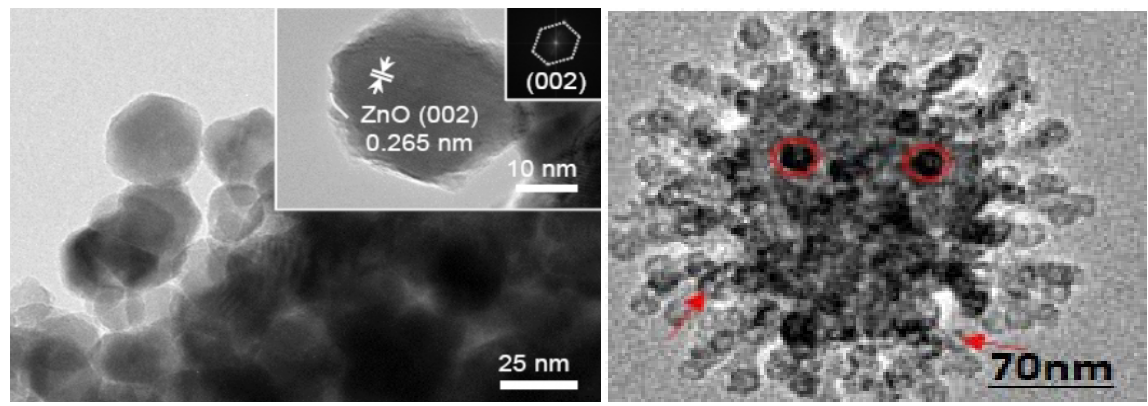

Figure 3. FE-TEM images with crystallinity and electron diffraction.

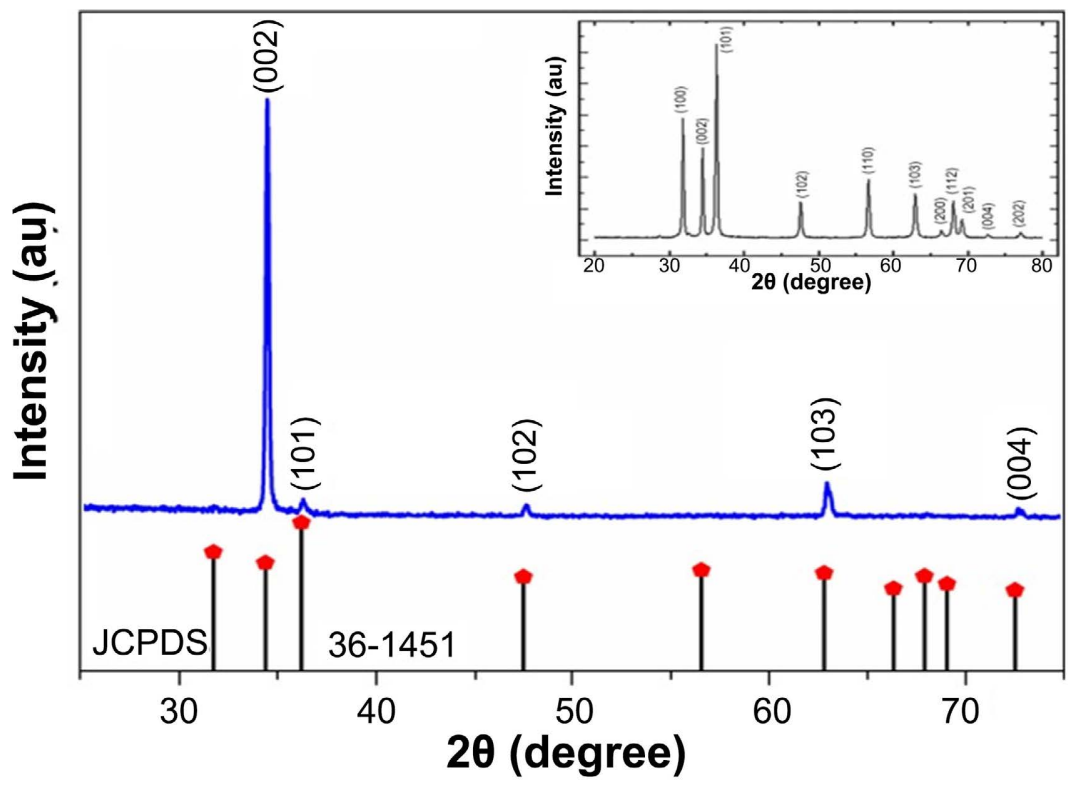

Figure 4. X-ray diffraction pattern of zinc oxide nanorod arrays. Notes: Inset shows the $\mathrm{X}$-ray diffraction pattern of zinc oxide nano powder.

analysis, synthesized $\mathrm{ZnO}$ nanoparticles consisted of $47.38 \% \mathrm{Zn}$ and $52.62 \% \mathrm{O}$ Compared with synthesized $\mathrm{ZnO}$ nanoparticles, hybrid- and nano- $\mathrm{ZnO}$ particles had $44.8 \%$ and $48.16 \% \mathrm{Zn}$ and $55.2 \%$ and $51.84 \%$ O, respectively. On XPS spectra, binding energy peaks of $\mathrm{Zn} 2 \mathrm{p}$ were detected at $1021 \mathrm{eV}$, and $1044 \mathrm{eV}$ for $\mathrm{Zn} 2 \mathrm{p} 3 / 2$ and $\mathrm{Zn} 2 \mathrm{p} 1 / 2$.

\section{Discussion}

Materials Wild-type T7 bacteriophage $\left(4.8 \times 1012 \mathrm{pfu} \cdot \mathrm{ml}^{-1}\right)$ was prepared by using a T7 select packaging kit (Novagen). Zinc oxide (purity $=95 \%$ ), SiO (purity $=99.99 \%), \mathrm{Zn}$ nanomaterial was synthesized with (purity $=98.5 \%$ ). The measured temperature of the solutions (away from the laser beam) is at $1 \mathrm{~min}$ intervals by using a mercury thermometer. We irradiated solutions of complex (300 $\mu \mathrm{g} \cdot \mathrm{ml}^{-1}$ ) in PBS ( $1 \mathrm{ml}$ ) by using a $1060 \mathrm{~nm}$ laser $(5 \mathrm{~W}$ ) (Figure 2 ). The measured temperature of the solutions (away from the laser beam) is at $1 \mathrm{~min}$ intervals by using a mercury thermometer. Structural analysis Structural characterization of the SZnOaAg complexes was performed by scanning electron microscopy (SEM) 
(JSM6700F; JEOL) (acceleration voltage: $20 \mathrm{kV}$ ), transmission electron microscopy (TEM) (JEM-3010; JEOL) (acceleration voltage: 200 or $300 \mathrm{kV}$ ) and by atomic force microscopy (AFM) (JSPM-4210; JEOL) using a tapping-mode cantilever. 2.3. Particle diameter analysis: the particle diameter of the complex was measured by dynamic light scattering (DLS) (LB-550; HORIBA). The complex was dissolved in distilled water $\left(300 \mu \mathrm{g} \cdot \mathrm{ml}^{-1}\right)$ and the solution was filtered through a cellulose acetate membrane (Advantec; pore size $=200 \mathrm{~nm}$ ) without filtration after $5 \mathrm{~d}$.

\subsection{Morphology, Crystallinity, Particle Size Distribution, and Atomic Composition}

The resulting nanoparticles exhibited uniform particle size and good mono-dispersibility. Synthesized $\mathrm{ZnO}$ nanoparticles generated spherical cluster shapes up to $3 \mu \mathrm{m}$ with average size was $48.3 \pm 3.5 \mathrm{~nm}$ in diameter with a narrow size distribution as shown in Figure 5. TEM image of mesoporous show interior spherical mesoporous silica cores with a diameter of $\sim 110 \mathrm{~nm}$; separated peripheral silica nanotubes perpendicular to the core surface with a length of $\sim 35 \mathrm{~nm}$ and outside/inside diameters of 10/2.5 nm, respectively (Figure 5 \& Figure 6 ). The size of the mesoporous silica cores can be tuned from $\sim 60$ to $160 \mathrm{~nm}$ by changing feeding amount of the surfactant (CTAB).

\subsection{Optical Property and Photoinduced Exothermicity of the CNH Complex}

Under NIR laser irradiation (1060 nm), aqueous suspensions of the CNH complexes $\left(300 \mu \mathrm{g} \cdot \mathrm{ml}^{-1}\right)$ exhibit a significant increase in temperature, whereas controls (without the SZnOAg complexes) showed a much smaller heating effect because of absorbance by water (Figure 7). Even on prolonged laser irradiation

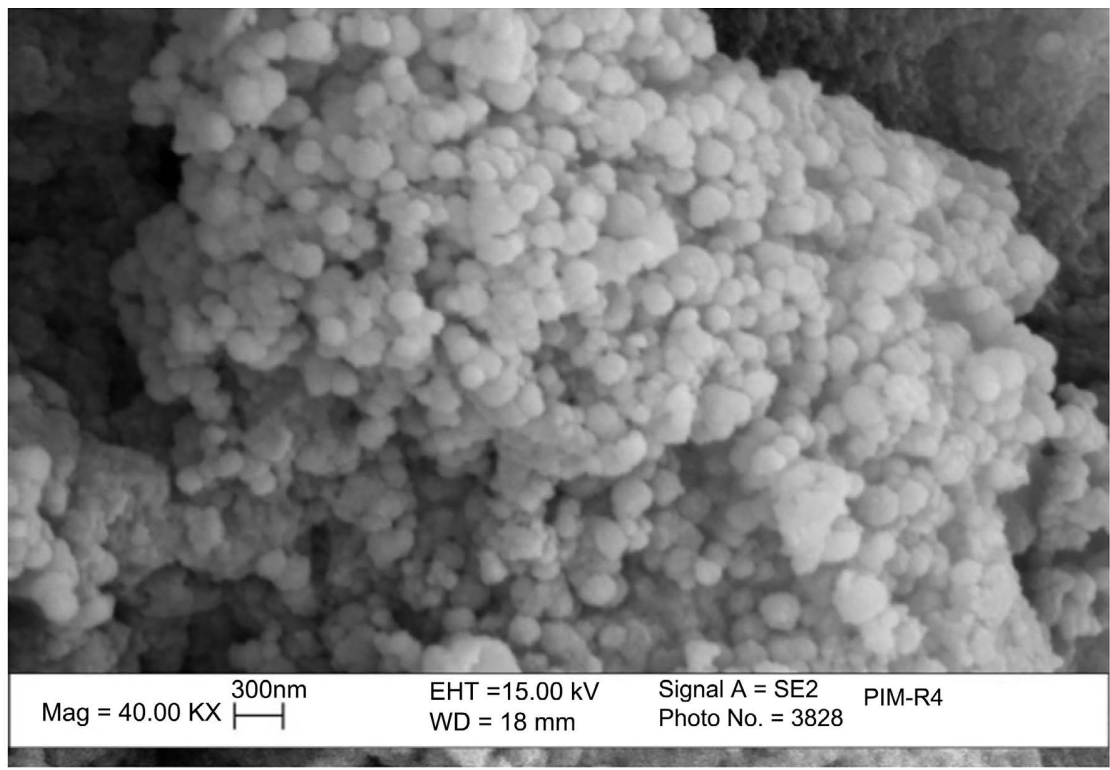

Figure 5. SEM image of mesoporous silica-zinc oxide nanomaterials. 


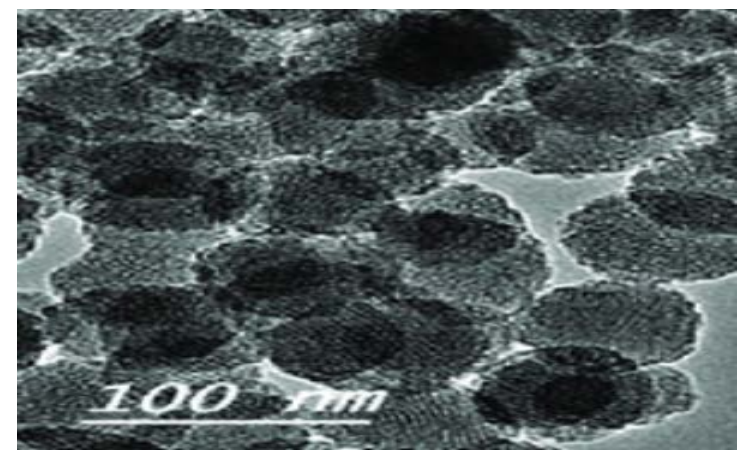

Figure 6. TEM image of mesoporous silica-zinc oxide nanomaterials.

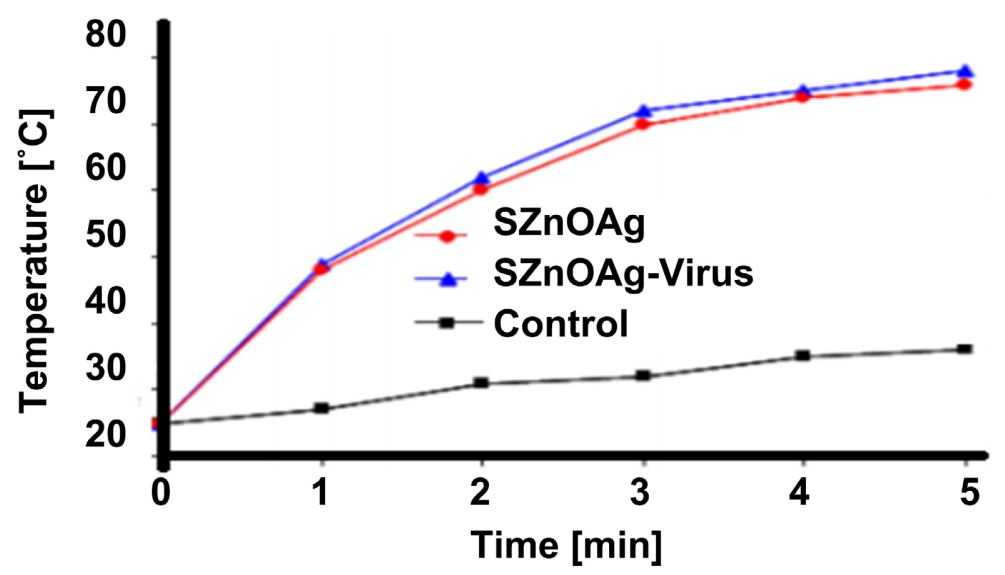

Figure 7. Temperature curves for a solution of NIR laser-induced exothermicity of SZnOAg and quercetin SZnOAg-virus complex (concentration $=300 \mu \mathrm{g} \cdot \mathrm{ml}^{-1}$ ) in PBS buffer alone (as a control) under continuous NIR laser irradiation $(1060 \mathrm{~nm}, 5 \mathrm{~W})$.

(60 min), there was no sedimentation of the complexes. These results confirm that the NIR laser driven on SZnOAg complexes act as a powerful exothermic material.

\section{Conclusion}

The high-efficiency cellular uptake of synthesized nanomaterial quercetin-SZnOAgvirus complex with excellent applications in the biomedical field was verified. The novel mesoporous silica nanoparticles can be easily synthesized and exhibited superior cellular uptake property, which on NIR laser irradiation effectively eliminates the virus. These results strongly suggest that functional nanomaterials could soon be produced that exhibit photo-exothermic elimination of harmful viruses, such as HIV, SARS, and avian influenza virus. The present work makes important progress for biomedical applications of nanomaterials in the field of omicron mutated Covid-19 antiviral material.

\section{Acknowledgements}

The corresponding author acknowledges a supporting moral help from Al Shujaa Bin Al Aslam School, Chemistry Department, students, and its School man- 
ager Mr. Naser Al Neamaa.

\section{Conflicts of Interest}

The authors declare no conflicts of interest regarding the publication of this paper

\section{References}

[1] Wang, W.X., Wang, P.Y., Tang, X.T., Elzatahry, A.A., Wang, S.W., Al-Dahyan, D., Zhao, M.Y., Yao, C., Hung, C.T., Zhu, X.H., et al. (2017) Facile Synthesis of Uniform Virus-Like Mesoporous silica Nanoparticles for Enhanced Cellular Internalization. ACS Central Science, 3, 839-846. https://doi.org/10.1021/acscentsci.7b00257

[2] Kargozar, S., Hoseini, S.J., Milan, P.B., Hooshmand, S., Kim, H.W. and Mozafari, M. (2020) Quantum Dots: A Review from Concept to Clinic. Biotechnology Journal, 15, Article ID: 2000117. https://doi.org/10.1002/biot.202000117

[3] Wang, J., Li, Y.Y. and Nie, G.J. (2021) Multifunctional Biomolecule Nanostructures for Cancer Therapy. Natural Reviewers Materials, 6, 766-783. https://doi.org/10.1038/s41578-021-00315-X

[4] Guan, B.Y., Yu, L. and Lou, X.W. (2016) Formation of Asymmetric Bowl-Like Mesoporous Particles via Emulsion-Induced Interface Anisotropic Assembly. Journal of the American Chemical Society, 138, 11306-11311. https://doi.org/10.1021/jacs.6b06558

[5] Li, Z.X., Barnes, J.C., Bosoy, A., Stoddart, J.F. and Zink, J.I. (2012) Mesoporous silica Nanoparticles in Biomedical Applications. Chemical Society Reviews, 41, 25902605. https://doi.org/10.1039/c1cs15246g

[6] Wang, R.Y., Zhang, Z.T., Liu, B.W., Xue, J.W., Liu, F.L., Tang, T.Z., Liu, W.Y., Feng, F. and Qu, W. (2021) Recent Advances in the Photothermal Applications of Two-Dimensional Nanomaterials: Photothermal Therapy and Beyond. Biomaterials Science, 9, 615-627.

[7] Stark, W.J. (2011) Nanoparticles in Biological Systems. Angewandte Chemie International Edition, 50, 1242-1258. https://doi.org/10.1002/anie.200906684

[8] Gao, J.H., Gu, H.W. and Xu, B. (2009) Multifunctional Magnetic Nanoparticles: Design, Synthesis, and Biomedical Applications. Accounts of Chemical Research, 42, 1097-1107. https://doi.org/10.1021/ar9000026

[9] Xia, F. and Jiang, L. (2008) Bio-Inspired, Smart, Multiscale Interfacial Materials. Advanced Materials, 20, 2842-2858. https://doi.org/10.1002/adma.200800836

[10] Niu, Y.T., Yu, M.H., Hartono, S.B., Yang, J., Xu, H.Y., Zhang, H.W., Zhang, J., Zou, J., Dexter, A., Gu, W.Y. and Yu, C.Z. (2013) Nanoparticles Mimicking Viral Surface Topography for Enhanced Cellular Delivery. Advanced Materials, 25, 6233-6237. https://doi.org/10.1002/adma.201302737

[11] Zhang, Z.J., Zhang, X., Xu, X.H., Li, Y.K., Li, Y.C., Zhong, D., He, Y.Y. and Gu, Z.W. (2015) Virus-Inspired Mimics Based on Dendritic Lipopeptides for Efficient Tumor-Specific Infection and Systemic Drug Delivery. Advanced Functional Materials, 25, 5250-5260. https://doi.org/10.1002/adfm.201502049

[12] Xia, T., Kovochich, M., Liong, M., Meng, H., Kabehie, S., George, S., Zink, J.I. and Nel, A.E. (2009) Polyethyleneimine Coating Enhances the Cellular Uptake of $\mathrm{Me}$ soporous silica Nanoparticles and Allows Safe Delivery of siRNA and DNA Constructs. ACS Nano, 3, 3273-3286. https://doi.org/10.1021/nn900918w

[13] Lin, J.Q., Zhang, H.W., Chen, Z. and Zheng, Y.G. (2010) Penetration of Lipid Mem- 
branes by Gold Nanoparticles: Insights into Cellular Uptake, Cytotoxicity, and Their Relationship. ACS Nano, 4, 5421-5429. https://doi.org/10.1021/nn1010792

[14] Jin, H., Heller, D.A., Sharma, R. and Strano, M.S. (2009) Size-Dependent Cellular Uptake and Expulsion of Single-Walled Carbon Nanotubes: Single Particle Tracking and a Generic Uptake Model for Nanoparticles. ACS Nano, 3, 149-158.

https://doi.org/10.1021/nn800532m

[15] Kievit, F.M. and Zhang, M. (2011) Surface Engineering of Iron Oxide Nanoparticles for Targeted Cancer Therapy. Accounts of Chemical Research, 44, 853-862. https://doi.org/10.1021/ar2000277

[16] Ni, D.L., Zhang, J.W., Bu, W.B., Xing, H.Y., Han, F., Xiao, Q.F., Yao, Z.W., Chen, F., He, Q.J., Liu, J.N., Zhang, S.J., Fan, W.P., Zhou, L.P., Peng, W.J. and Shi, J.L. (2014) Dual-Targeting Upconversion Nanoprobes across the Blood-Brain Barrier for Magnetic Resonance/Fluorescence Imaging of Intracranial Glioblastoma. ACS Nano, 8, 1231-1242. https://doi.org/10.1021/nn406197c

[17] Nel, A.E., Madler, L., Velegol, D., Xia, T., Hoek, E.M.V., Somasundaran, P., Klaessig, F., Castranova, V. and Thompson, M. (2009) Understanding Biophysicochemical Interactions at the Nano-Bio Interface. Nature Materials, 8, 543-557. https://doi.org/10.1038/nmat2442

[18] Duan, X.P. and Li, Y.P. (2012) Physicochemical Characteristics of Nanoparticles Affect Circulation, Biodistribution, Cellular Internalization, and Trafficking. Small, 9, 1521-1532. https://doi.org/10.1002/smll.201201390

[19] Schöttler, S., Becker, G., Winzen, S., Steinbach, T., Mohr, K., Landfester, K., Mailander, V. and Wurm, F.R. (2016) Protein Adsorption Is Required for Stealth Effect of Poly(Ethylene Glycol)- and Poly(Phosphoester)-Coated Nanocarriers. Nature Nanotechnology, 11, 372-377. https://doi.org/10.1038/nnano.2015.330

[20] Welsher, K. and Yang, H. (2014) Multi-Resolution 3D Visualization of the Early Stages of Cellular Uptake of Peptide-Coated Nanoparticles. Nature Nanotechnology, 9, 198-203. https://doi.org/10.1038/nnano.2014.12

[21] Yang, K. and Ma, Y.Q. (2010) Computer Simulation of the Translocation of Nanoparticles with Different Shapes across a Lipid Bilayer. Nature Nanotechnology, 5, 579-583. https://doi.org/10.1038/nnano.2010.141

[22] Jiang, W., Kim, B.Y.S., Rutka, J.T. and Chan, W.C.W. (2008) Nanoparticle-Mediated Cellular Response Is Size-Dependent. Nature Nanotechnology, 3, 145-150. https://doi.org/10.1038/nnano.2008.30

[23] Agarwal, R., Singh, V., Jurney, P., Shi, L., Sreenivasan, S.V. and Roy, K. (2013) Mammalian Cells Preferentially Internalize Hydrogel Nanodiscs over Nanorods and Use Shape-Specific Uptake Mechanisms. Proceedings of the National Academy of Sciences of the United States of America, 110, 17247-17252.

https://doi.org/10.1073/pnas.1305000110

[24] Zhang, J., Yuan, Z.F., Wang, Y., Chen, W.H., Luo, G.F., Cheng, S.X., Zhuo, R.X. and Zhang, X.Z. (2013) Multifunctional Envelope Type Mesoporous silica Nanoparticles for Tumor-Triggered Targeting Drug Delivery. Journal of the American Chemical Society, 135, 5068-5073. https://doi.org/10.1021/ja312004m

[25] Walkey, C.D. and Chan, W.C.W. (2012) Understanding and Controlling the Interaction of Nanomaterials with Proteins in a Physiological Environment. Chemical Society Reviews, 41, 2780-2799. https://doi.org/10.1039/C1CS15233E

[26] Han, H.S., Martin, J.D., Lee, J., Harris, D.K., Fukumura, D., Jain, R.K. and Bawendi, M. (2012) Spatial Charge Configuration Regulates Nanoparticle Transport and Binding Behavior in Vivo. Angewandte Chemie International Edition, 52, 1414-1419. 
https://doi.org/10.1002/anie.201208331

[27] Zhang, S.L., Li, J., Lykotrafitis, G., Bao, G. and Suresh, S. (2009) Size-Dependent Endocytosis of Nanoparticles. Advanced Materials, 21, 419-424.

https://doi.org/10.1002/adma.200801393

[28] Albanese, A. and Chan, W.C.W. (2011) Effect of Gold Nanoparticle Aggregation on Cell Uptake and Toxicity. ACS Nano, 5, 5478-5489. https://doi.org/10.1021/nn2007496

[29] Nileeka Balasuriya, B.W. and Vasantha Rupasinghe, H.P. (2020) Plant Flavonoids as Angiotensin Converting Enzyme Inhibitors in Regulation of Hypertension. Functional Foods in Health and Disease, 1, 172-188.

[30] Abian, O., Ortega-Alarcon, D., Jimenez-Alesanco, A., Ceballos-Laita, L., Vega, S., Hugh, T., et al. (2020) Structural Stability of SARS-CoV-2 3CLpro and Identification of Quercetin as an Inhibitor by Experimental Screening. International Journal of Biological Macromolecules, 164, 1693-1703.

https://doi.org/10.1016/j.ijbiomac.2020.07.235

[31] Rancan, F., Gao, Q., Graf, C., Troppens, S., Hadam, S., Hackbarth, S., Kembuan, C., Blume-Peytavi, U., Rühl, E., Lademann, J. and Vogt, A. (2012) Skin Penetration and Cellular Uptake of Amorphous silica Nanoparticles with Variable Size, Surface Functionalization, and Colloidal Stability. ACS Nano, 6, 6829-6842.

https://doi.org/10.1021/nn301622h

[32] Song, H., Ahmad Nor, Y., Yu, M., Yang, Y., Zhang, J., Zhang, H.W., Xu, C., Mitter, N. and Yu, C.Z. (2016) Silica Nanopollens Enhance Adhesion for Long-Term Bacterial Inhibition. Journal of the American Chemical Society, 138, 6455-6462. https://doi.org/10.1021/jacs.6b00243

[33] Ahmad Nor, Y., Niu, Y.T., Karmakar, S., Zhou, L., Xu, C., Zhang, J., Zhang, H.W., Yu, M.H., Mahony, D., Mitter, N., Cooper, M.A. and Yu, C.Z. (2015) Shaping Nanoparticles with Hydrophilic Compositions and Hydrophobic Properties as Nanocarriers for Antibiotic Delivery. ACS Central Science, 1, 328-334. https://doi.org/10.1021/acscentsci.5b00199

[34] Mura, S., Nicolas, J. and Couvreur, P. (2013) Stimuli-Responsive Nanocarriers for Drug Delivery. Nature Materials, 12, 991-1003. https://doi.org/10.1038/nmat3776 